\title{
Fluoride: Is It Worth to be added in Pit and Fissure Sealants?
}

AR Prabhakar, Prasanna T Dahake, OS Raju, N Basappa

\begin{abstract}
Background and objectives: Fluoride is being used for the prevention of dental caries since a long time. Incorporation of fluoride in pit and fissure sealants has been found to reduce initiation and progression of pit and fissure caries. Authors conducted this study to evaluate and compare the effect of fluoride releasing pit and fissure sealants on the inhibition of demineralization of adjacent enamel and to reduce wall lesion frequency.
\end{abstract}

Materials and methods: A total of 60 caries-free human third molars were randomly assigned into three groups receiving conventional resin sealant without fluoride (Group A), fluoride releasing resin sealant (Group B), glass ionomer pit and fissure sealant (Group C). Fissure cavities of $5 \times 2 \times 1.5 \mathrm{~mm}$ were prepared on buccal surfaces of teeth using fissurotomy bur and sealants were applied onto the cavities.

The teeth were then thermocycled and exposed to acidified gelatin gel for 6 weeks to induce caries like lesions. A $150 \mu \mathrm{m}$ section was taken from each tooth and observed under polarized light microscope to measure the depth of advancing front of outer enamel lesion. The outer lesion depths of all three groups were compared.

Results: Enamel demineralization was least in glass ionomer pit and fissure sealant while the demineralization exhibited by nonfluoridated resin and fluoridated resin were comparable. Wall lesion frequency was found to be $0 \%$ in all groups.

Conclusion and interpretation: The glass ionomer pit and fissure sealant exhibited highest anticariogenic efficacy and hence can be advocated as a means of preventing dental caries.

Keywords: Dental caries, Pit and fissure sealants, Fluorides.

How to cite this article: Prabhakar AR, Dahake PT, Raju OS, Basappa N. Fluoride: Is It Worth to be added in Pit and Fissure Sealants?. Int J Clin Pediatr Dent 2012;5(1):1-5.

Source of support: Nil

Conflict of interest: None declared

\section{INTRODUCTION}

Dental caries is the most prevalent chronic disease affecting the human race. ${ }^{1}$ Dental caries remains the singlemost common disease of childhood, occurring five to eight times more commonly than asthma, which is the second most common disease of childhood. ${ }^{2}$

Occlusal surface represents $12.5 \%$ of total surface of permanent dentition but accounts for more than $50 \%$ of caries in school children. Occlusal pits and fissures are the areas of caries initiation. Attempts are being made since a long time to prevent initiation and progression of pit and fissure caries by various means. ${ }^{3}$ Introduction of Bis-GMA has revolutionized the pit and fissure sealant treatment. Since then, many advancements have been made to improve their adhesive and mechanical properties. Pit and fissure sealants are an economical and adequate means for prevention of dental caries on occlusal surface of molars and premolars and to maintain dental health. Various other materials like flowable composites, glass ionomer cements, resin-modified glass ionomer cements, compomers and different types of bonding agents have also been used nowadays as pit and fissure sealants.

The topical and systemic fluorides are effective in reducing the smooth surface caries but are ineffective in preventing pits and fissures caries. ${ }^{4}$ Incorporation of fluorides in pit and fissure sealants has been found to play a promising role in the reduction of pit and fissure caries, thereby reducing overall caries incidence. Different types of fluoride releasing pit and fissure sealants can be used to protect smooth surfaces, hypoplastic enamel and areas around orthodontic brackets. Considering these advantages, use of sealants is advocated in various public health prevention measures and has to be proved successful. ${ }^{5}$

Hence, the present study was conducted to evaluate and compare the potential of fluoride releasing pit and fissure sealants on the inhibition of demineralization of adjacent enamel and to reduce wall lesion frequency.

\section{MATERIALS AND METHODS}

A total of 60 third molars extracted for therapeutic purpose were included in the study. All the teeth were evaluated under a stereomicroscope (Leica Wild M3Z, Germany) to ensure the absence of white spot lesions or caries, developmental defects, microfractures and discoloration. ${ }^{6}$ All the samples were stored in $0.01 \%$ thymol solution ${ }^{7}$ to achieve disinfection and prevent dehydration. Fluoride-free prophylaxis $^{8}$ was done and teeth were stored in double deionized distilled water at room temperature until further use.

The samples were divided into three groups-A, B and $\mathrm{C}$, each containing 20 teeth. On the middle third of buccal surface of each of the third molar tooth, fissure cavity ${ }^{9}$ was prepared using Fissurotomy bur (SS White Burs, Lakewood, NJ) and a high speed handpiece (NSK, PANA AIR) of size $5 \times 2 \times 1.5 \mathrm{~mm}$ without bevel or feather edge preparation. The dimensions of the cavity were measured with a William's periodontal probe (Hu-Friedy PQW6, USA) to 


\begin{tabular}{clll} 
& & \multicolumn{2}{c}{ Table 1: Color coding of groups along with pit and fissure sealants } \\
\hline Sr. no. & Group & Color coding & Pit and fissure sealant \\
\hline 1. & Group A & Red & Nonfluoridated resin sealant (Helioseal ${ }^{\circledR}$ pit and fissure sealant) \\
2. & Group B & Green & Fluoride-releasing resin sealant (Guardian Seal TM $_{\text {pit and fissure sealant) }}$ \\
3. & Group C & Pink & Glass ionomer pit and fissure sealant (GC Fuji VII \\
\hline
\end{tabular}

ensure uniformity of the enamel window in all the samples. All the three groups were color coded for identification as per shown in Table 1 and filled with pit and fissure sealants according to manufacturers' instructions.

\section{Application of Sealants to the Cavities}

- Group A (Nonfluoridated pit and fissure sealant; Helioseal ${ }^{\circledR}$ pit and fissure sealant): The cavity in each sample was acid etched ${ }^{10}$ with $37 \%$ phosphoric acid gel for 30 seconds, ${ }^{11}$ rinsed with double deionized distilled water for 10 seconds and dried with oil-free compressed air for 10 seconds. The material was then placed in the cavity of each tooth with the manufacturer's direct delivery system up to cavosurface margin and light cured for 40 seconds with light curing unit (Bee Cool, Plus Top light - LED light curing unit, Taiwan).

- Group B (Fluoride-releasing pit and fissure sealant, Guardian Seal ${ }^{\mathrm{TM}}$ pit and fissure sealant): The same procedure as described for group A was followed with respect to the samples belonging to group $\mathrm{B}$.

- Group C (Glass ionomer pit and fissure sealant, GC Fuji VII ${ }^{\mathrm{TM}}$ GI pit and fissure sealant): The cavity of each sample was cleaned for 15 seconds with cavity conditioner, ${ }^{12}$ rinsed with double deionized distilled water for 10 seconds and dried with oil-free compressed air for 10 seconds. The powder and liquid were mixed according to manufacturer's instructions and placed into cavities. Excess material was removed with plastic instrument and light cured for 40 seconds (Bee Cool, Plus Top light - LED light curing unit, Taiwan). All the surfaces of molars were coated with acid resistant varnish leaving $1 \mathrm{~mm}$ rim of exposed sound enamel surrounding the sealant-filled cavities and subjected to thermocycling ${ }^{13}$ in artificial saliva. ${ }^{14}$

Samples were suspended in acidified gelatin ge ${ }^{15}$ for 6 weeks at $37^{\circ} \mathrm{C}$ to induce artificial caries like lesion on exposed enamel rim. The acidified gelatin gel was changed at weekly interval, as $\mathrm{pH}$ of solution gets altered with time. Each tooth was then cleaned thoroughly with double deionized distilled water.

Longitudinal tooth section of $150 \mu \mathrm{m}$ thickness was obtained by cutting through the enamel window of tooth using a Silverstone-Taylor hard tissue microtome (Leica SP 1600, Leica Microsystems, Nussloch, Germany). The section was mounted on glass slide and evaluated under polarized light microscope (Leica, Leica Microsystems, Nussloch, Germany). ${ }^{16}$

\section{Quantification of the Lesions using Leica QWin Software}

Each section was examined under polarized light microscope and photomicrograph of each section was taken. The mean lesion depths of caries like lesions were determined in a blinded fashion by projecting the photomicrographs onto a computer interfaced digitized tablet and measuring 10 points along the advancing front lesions. Using the same protocol, the presence or absence of wall lesions was determined for each specimen. The advancing front along the body of the outer surface lesion was measured, with the first measurement located 100 micrometers from the cavity preparation (Fig. 1).

For statistical analysis, one-way ANOVA was used for multiple group comparisons followed by post hoc Tukey's test for groupwise comparison (A vs B, A vs C, B vs C). The results were expressed as mean $\pm \mathrm{SD}$, coefficient of variation and range values.

\section{RESULTS}

Table 2 and Figure 2 show the mean depths of the outer lesions from the three treatment groups. The mean depth of outer lesions was compared using ANOVA and post-hoc Tukey's test for groupwise comparison (significance level of $\mathrm{p}<0.05$ ).

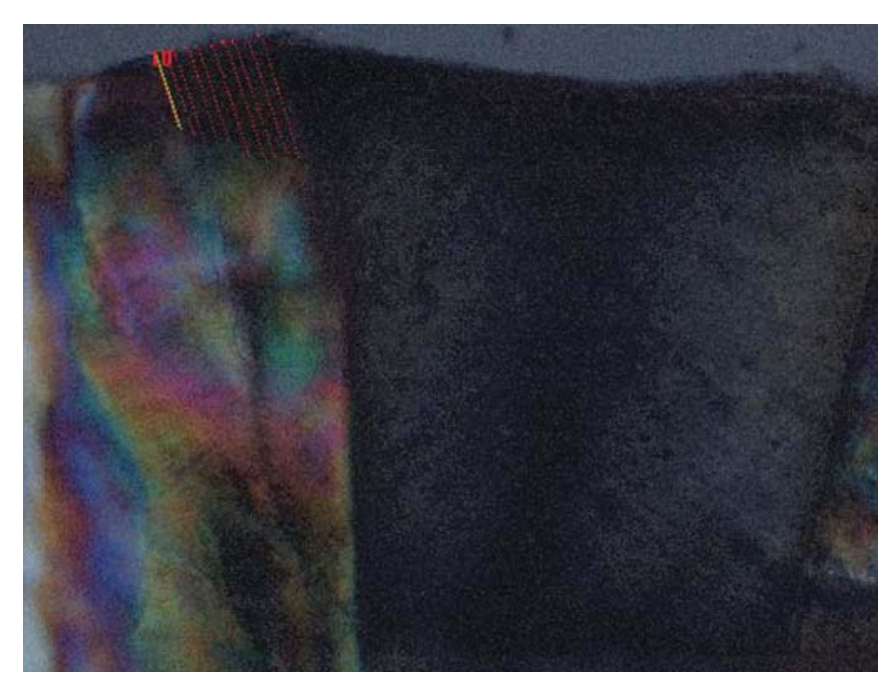

Fig. 1: Photomicrograph showing measurement of advancing front of caries like lesions at 10 points 
Fluoride: Is It Worth to be added in Pit and Fissure Sealants?

Table 2: Descriptive statistics showing the intergroup comparison of the significance p-values of difference in demineralization among three experimental groups

\begin{tabular}{lccccc}
\hline Groups & $\begin{array}{c}\text { Demineralization } \\
\text { Mean } \pm \text { SD }\end{array}$ & \multicolumn{2}{c}{ Difference between groups } & Significance \\
\cline { 2 - 5 } & & Groups compared & Mean difference & $p$-value* & \\
\hline Group A & $214.44 \pm 97.44$ & A-B & 8.29 & 0.93 NS & $p>0.05$ \\
Group B & $222.73 \pm 80.66$ & A-C & 58.45 & 0.049 S & $p<0.05$ \\
Group C & $155.99 \pm 37.87$ & B-C & 66.74 & 0.021 S & $p<0.05$ \\
\hline
\end{tabular}

ANOVA F $=4.51 ; p<0.05$; S: Significant; $p>0.05 ;$ NS: Not significant; *: Post-hoc Tukey's test; SD: Standard deviation

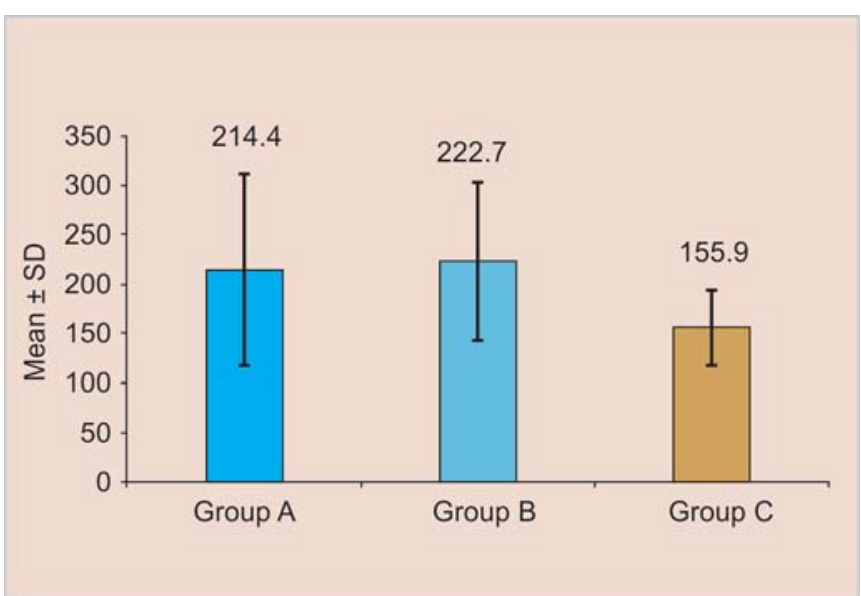

Fig. 2: Mean demineralization values of groups A, B and C

The mean outer lesion depth was the least for group C (glass ionomer pit and fissure sealant) at $73 \%$. The difference in outer lesion depth of group $\mathrm{C}$ with that of the remaining groups was found to be significant. As shown in Table 3, the outer lesions adjacent to cavities filled with the conventional nonfluoride-containing sealant had a reduction of 3\% in depth when compared with those filled with fluoride-releasing sealant. The outer lesions adjacent to the cavities filled with glass ionomer sealant had a reduction of $27 \%$ in depth when compared with the conventional nonfluoride-containing sealant. The glass ionomer sealant group also had a 30\% reduction in outer lesion depth when compared with the fluoride-releasing sealant group. The percentage of reduction was calculated by dividing the mean lesion depth for the treatment group by the mean lesion depth for the control group and multiplying the result by $100 \%$.

\section{DISCUSSION}

Pits and fissures are more vulnerable to caries initiation due to variation in shapes, tortuousness with invaginations or irregularities and narrowness ( $0.1 \mathrm{~mm}$ wide). As a result these are ideal sites for the retention of bacteria and food remnants, rendering mechanical means of debridement inaccessible as toothbrush bristle $(0.2 \mathrm{~mm})$ is too large to penetrate most of the fissures. ${ }^{4}$

Attempts were made to prevent pit and fissure caries by various means like prophylactic odontotomy, enameloplasty, use of topical and systemic fluorides and various adhesive materials like cements and resins. ${ }^{4}$ Use of pit and fissure sealants was thus conceptualized to prevent initiation of caries in fissures which is conservative modality of caries prevention. ${ }^{17}$ The cariostatic properties of sealants are attributed to the physical obstruction of the pits and fissures preventing colonization of new bacteria and penetration of fermentable carbohydrates, so that remaining bacteria cannot produce acid in cariogenic concentration. ${ }^{18}$ The role of fluoride released from dental materials in the prevention of caries ${ }^{19}$ has been evidenced from in vitro and in vivo studies, supporting the contention that frequent supply of $\mathrm{F}^{-}$at low concentration decrease the enamel demineralization and accelerates the remineralization process. ${ }^{20}$

Although other agents, such as fluoridated varnishes, dentifrices, mouth rinses and gels can reduce the prevalence of caries, the fluoride released from dental materials also plays a promising role in caries prevention. ${ }^{21,22}$ The ability of a dental material to act as a fluoride reservoir is a distinct advantage in caries resistance, both at the enamel restorative interface and adjacent to the outer enamel surface near the

Table 3: Effect of fluoride release from sealant material on enamel demineralization and wall lesion frequency

\begin{tabular}{lccc}
\hline Sealant & $\begin{array}{c}\text { Mean outer lesion } \\
\text { depth (micrometers) }\end{array}$ & $\begin{array}{c}\text { Wall lesion } \\
\text { frequency }\end{array}$ & Reduction in outer lesion depth \\
\hline $\begin{array}{l}\text { Group A (nonfluoridated pit } \\
\text { and fissure sealant) }\end{array}$ & $214.44 \pm 97.44$ & $0 \%$ & $\begin{array}{l}3 \% \text { when compared with fluoride-releasing } \\
\text { sealant }\end{array}$ \\
$\begin{array}{l}\text { Group B (fluoridated pit and } \\
\text { Group C (glass ionomer pit } \\
\text { and fissure sealant) }\end{array}$ & $222.73 \pm 80.66$ & $0 \%$ & $\begin{array}{l}27 \% \text { when compared with conventional } \\
\text { nonfluoride-containing sealant } \\
30 \% \text { when compared with the fluoride- } \\
\text { releasing sealant group }\end{array}$ \\
\hline
\end{tabular}


fluoride-releasing dental material. ${ }^{23,24}$ Glass ionomer cement (GIC) is shown to release fluoride slowly over a period of time ${ }^{25}$ into the surrounding enamel yielding cariostatic effects. ${ }^{26}$ Chemical bonding of GIC to enamel and dentin without etching is the additional advantage, making it much easier to handle. ${ }^{12}$ Because of its well-known cariostatic effect, attempts were made consistently for more than 25 years to add fluoride in resin sealants ${ }^{27}$ and efforts to combine the two continue today. ${ }^{28}$

In the present study, glass ionomer pit and fissure sealant has shown highest inhibition of demineralization of adjacent enamel. The difference in inhibition of demineralization between glass ionomer pit and fissure sealant and fluoridated and nonfluoridated resin sealant was statistically significant. The result is attributed to $\mathrm{F}^{-}$released from glass ionomer cement by means of three discrete mechanisms: Surface wash off, diffusion through pores and cracks and bulk diffusion. ${ }^{29}$ Similar findings were confirmed by some in vitro and in vivo studies showing a sustained fluoride release from GIC to the surrounding dental structures ${ }^{30}$ and tooth microenvironment. ${ }^{31}$ Study evaluating GIC as pit and fissure sealants clinically has proved to reduce caries susceptibility. ${ }^{32}$

There was no significant inhibition of demineralization seen between fluoridated as well as nonfluoridated resin sealants thus, confirming previous results. ${ }^{30,33}$

The above findings could be explained by the differences in the composition between ionomeric and resinous materials, resulting in subsequent differences in fluoride releasing profiles. ${ }^{33}$ Diffusion of water into the material is necessary for the formation of hydrogen ions that attack the fluoride-containing glass particles, releasing fluoride. That is why ionomeric materials are more permeable to water, enhancing fluoride diffusion and release. ${ }^{34}$ On the other hand, the matrix of resinous sealants is much less hydrophilic, making fluoride release more difficult. ${ }^{35}$

No wall lesions were found in any of the specimens in this study. Absence of wall lesions may be justified due to reduction of microleakage along the tooth-sealant material interface due to acid etching or conditioning of enamel. Micropores and microprojections are created on enamel surface causing penetration and polymerization of sealants in these areas, forming a mechanical bond with the tooth. Optimal bonding of resin sealants to enamel depends on proper and adequate conditioning of enamel. ${ }^{36}$ The result obtained in this study can be confirmed by other studies showing that the sealants exhibited small or no dye microleakage at the interface between sealant and dental enamel. $^{37}$
Depending on the environment, all pit and fissure sealants may act differently due to other variables like preparation of fissures, enamel etching and conditioning, application of bonding agents and contamination of prepared surfaces of fissures. Appropriate method of application of sealants is also a determining factor to reduce the microleakage thus, reducing wall lesion, which may further lead to formation of secondary caries.

\section{CONCLUSION}

- The inhibition of demineralization in enamel adjacent to glass ionomer pit and fissure sealants was the highest followed by fluoridated and nonfluoridated resin sealants.

- The inhibition of demineralization in enamel adjacent to fluoridated and nonfluoridated resin sealants was comparable.

- No wall lesions were found in any of the specimens in all of the pit and fissure sealants.

\section{REFERENCES}

1. Newbrun E. History and early theories of the etiology of caries. In: Newbrun E (Ed). Cardiology (3rd ed). Chicago: Quintessence; 1989. $13-28 \mathrm{p}$.

2. Mc-Donald RE, Avery DR, Stookey GK. Dental caries in the child and adolescent. In: McDonald RE, Avery DR, Dean JA, editors. Dentistry for the child and adolescent (8th ed). New Delhi: Elsevier; 2005. 203-235 p.

3. Hicks J, Flaitz CM. Pit and fissure sealants and conservative adhesive restorations: Scientific and clinical rationale. In: Pinkham JR, Casamassimo PS, McTigue DJ, Fields, Jr, HW, Nowak AJ, editors. Pediatric Dentistry Infancy through Adolescence (4th ed). New Delhi: Saunders An Imprint of Elsevier; 2005. 520-576 p.

4. Nikiforuk G. Occlusal sealants. In: Nikiforuk G (Ed). Understanding dental caries, etiology and mechanisms, basic and clinical aspects. New York: Karger 1985;2:145-173.

5. Salar DV, Garcia-Godoy F, Flaitz CM, Hicks MJ. Potential inhibition of demineralization in vitro by fluoride releasing sealants. J Am Dent Assoc 2007;138(4):502-506.

6. Ellwood RP, O'Mullane D. The association between developmental enamel defects and caries in populations with and without fluoride in their drinking water. J Public Health Dent 1996;56(2):76-80.

7. Moura JS, Rodrigues LKA, Del Bel Cury AA, Lima EMCX, Garcia RMCR. Influence of storage solution on enamel demineralization submitted to $\mathrm{pH}$ cycling. J Appl Oral Sci 2004;12(3):205-208.

8. Ansari G, Oloomi K, Eslami B. Microleakage assessment of pit and fissure sealant with and without the use of pumice prophylaxis. Int J Pediatr Dent 2004;14(4):272-278.

9. Garcia-Godoy F, de Araujo FB. Enhancement of fissure sealant penetration and adaptation: The enameloplasty technique. J Clin Pediatr Dent 1994;19(1):13-18.

10. Salama FS, Al-Hammad NS. Marginal seal and compomer materials with and without enameloplasty. Int J Pediatr Dent 2002;12(1):39-46. 
11. Buonocore MG. A Simple method of increasing the adhesion of acrylic filling materials to enamel surfaces. J Dent Res 1955;34(6):849-853.

12. Aboush YE, Jenkins CBG. An evaluation of the bonding of glass ionomer restoratives to dentin and enamel. Br Dent J 1986; 161(5):179-184.

13. Smith LA, O’brain JA, Retief DH, Marchman JL. Microleakage of two dentinal bonding restorative systems. J Dent Res 1988;67:309.

14. el Mallakh BF, Sarkar NK. Fluoride release from glass ionomer cements in deionized water and artificial saliva. Dent Mater 1990;6(2):118-22.

15. Kidd E. The early carious lesion in enamel. In: Murray JJ (Ed). The prevention of dental diseases. Oxford, England: University Press, 1983:192-217.

16. Arends J, ten Bosch JJ. Demineralization and remineralization evaluation technique. J Dent Res 1992;71:924-928.

17. Gordon PH, Nunn JH. Fissure sealants. In: Murray JJ (Ed). The prevention of oral disease (3rd ed). New York: Oxford University Press;1996. 78-94 p.

18. Sanders BJ, Feigal RJ, Avery DR. Pit and fissure sealants and preventive resin restorations. In: Mc-Donald RE, Avery DR, Dean JA (Ed). Dentistry for the child and adolescent (8th ed). New Delhi: Elsevier 2005:355.

19. Jensen ME, Wefel JS, Triolo PT, Hammesfahr PD. Effects of a fluoride-releasing sealant on artificial enamel caries. Am J Dent 1990;3(2):75-78.

20. Page DJ. A study of the effect of fluoride delivered from solution and dentifrices on enamel demineralization. Caries Res 1991;25(4):251-55.

21. Cain K, Hicks J, English J, Flaitz C, Powers JM, Rives T. In vitro enamel caries formation and orthodontic bonding agents. Am J Dent 2006;19(3):187-192.

22. Bynum AM, Donly KJ. Enamel de/remineralization on teeth adjacent to fluoride releasing materials without fluoride dentifrice exposure. ASDC J Dent Child 1999;66(2):89-92.

23. Francci C, Deaton TC, Arnold RR, Swift EJ Jr, Perdigao J, Bawden JW. Fluoride release from restorative materials and its effects on dentin demineralization. J Dent Res 1999;78(10): 16471654.

24. Donly KJ. Enamel and dentin demineralization inhibition of fluoridereleasing materials. Am J Dent 1994;7(5):275-278.

25. Swartz ML, Philips RW, Clark HE. Long-term fluoride release from glass ionomer cements. J Dent Res 1984;63(2):158-160.

26. Garcia-Godoy F. Preventive glass ionomer restorations. Am J Dent 1988;1(3):97-99.

27. Lee H, Ocumpaugh DE, Swartz ML. Sealing of developmental pits and fissures: II. Fluoride release from flexible fissure sealants. J Dent Res 1972;51(1):183-190.
28. Rock WP, Foulkes EE, Perry H, Smith AJ. A comparative study of fluoride releasing composite resin and glass ionomer materials used as fissure sealants. J Dent 1996;24(4):275-280.

29. Kuhn AT, Wilson AD. The diffusion mechanism of silicate and glass ionomer dental cements. Biomaterials 1985;6(6):378-382.

30. Wessenberg $\mathrm{G}$, Hals E. The in vitro effect of glass ionomer cement on dentin and enamel walls. J Oral Rehabil 1980;7(1):35-42.

31. Hatibovic-Kofman S, Koch G, Ekstrand J. Glass ionomer materials as rechargeable fluoride release system. Int J Paediatr Dent 1997;7(2):65-73.

32. Arrow P, Riordan PJ. Retention and caries preventive effects of a GIC and a resin-based fissure sealant. Community Dent Oral Epidemiol 1995;23(5):282-285.

33. Glasspoole EA, Erickson RL, Davidson CL. Demineralization of enamel in relation to the fluoride release of materials. Am J Dent 2001;14(1):8-12.

34. Asmussen E, Peutzfeldt A. Long-term fluoride release from glass ionomer cement, a compomer, and from experimental resin composites. Acta Odontol Scand 2002;60(2):93-97.

35. Preston AJ, Agalamanyi EA, Higham SM, Mair LH. The recharge of esthetic dental restorative materials with fluoride in vitro - two years’ results. Dent Mater 2003;19(1):32-37.

36. Roydhouse RH. Prevention of occlusal fissure caries by use of a sealant: A pilot study. ASDC J Dent Child 1968;35(3):253-262.

37. Hatibovivic-Kofman S, Wrigth GZ, Braverman I. Microleakage of sealants after conventional, bur, and air-abrasion preparation of pits and fissures. Pediatr Dent 1998;20(3):173-176.

\section{ABOUT THE AUTHORS}

\section{AR Prabhakar (Corresponding Author)}

Professor and Head, Department of Pedodontics and Preventive Dentistry, Bapuji Dental College and Hospital, Davangere-577004 Karnataka, India, e-mail: attiguppeprabhakar@gmail.com

\section{Prasanna T Dahake}

Postgraduate Student, Department of Pedodontics and Preventive Dentistry, Bapuji Dental College and Hospital, Davangere, Karnataka India

\section{OS Raju}

Professor, Department of Pedodontics and Preventive Dentistry, Bapuji Dental College and Hospital, Davangere, Karnataka, India

\section{N Basappa}

Professor, Department of Pedodontics and Preventive Dentistry, Bapuji Dental College and Hospital, Davangere, Karnataka, India 